The effects of simultaneous use of pre-planning along + /-Here-and-Now dimension on fluency, complexity, and accuracy of Iranian EFL learners' written performance

\author{
Mohammadzadeh Mohammadabadi, AliReza \\ Faculty of Foreign Languages, University of Isfahan, Iran (ali.mohammadzadeh61@gmail.com) \\ Dabaghi, Azizallah \\ Faculty of Foreign Languages, University of Isfahan, Iran (dabaghi@fgn.ui.ac.ir)
}

Tavakoli, Mansoor

Faculty of Foreign Languages, University of Isfahan, Iran (mr.tavakoli14@gmail.com)

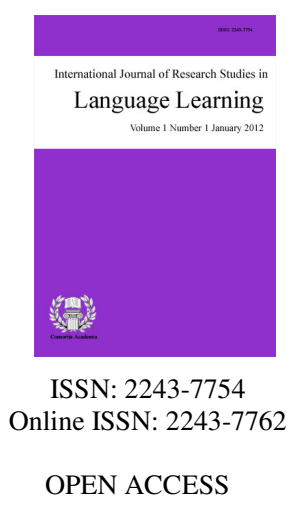

Received: 4 August 2012

Revised: 9 September 2012

Accepted: 5 October 2012

Available Online: 7 October 2012

DOI: $10.5861 /$ ijrsll.2012.168

\title{
Abstract
}

Nowadays, plethora of research on pre-task planning has attempted to find out the effect of planning time on oral production of L2 learners. By and large, it has been reported planning has had a positive impact on their task-performance. Nonetheless, there have been few bodies of research performed with regard to planning in writing contexts, and there has been no conclusive evidence to illustrate the fact that pre-task planning enhances L2 learners' written performance in the ways which lots of researchers have reported for the context of L2 oral performance. The study reported was primarily aimed at investigating the effects of simultaneous use of planning along $+/$-Here-and-Now on fluency, accuracy, and complexity of written performance. Particularly, the effects of + --planning merged with $+/$-Here-and-Now (i.e. planned here-and-now, unplanned here-and now and planned there-and-then as well as unplanned there-and-then conditions) on Iranian EFL learners` writing accuracy, fluency, and complexity were investigated. Study participants were 30 male and female Iranian of lower-intermediate EFL learners whose mother tongue was Persian and whose age group ranged between 18 and 26. Participants were assigned to four experimental conditions mentioned above. Participants in all four conditions were engaged in a written narrative task in which four different wordless picture stories were chosen for data collection and control of the practice effects. The results obtained from one-way ANOVAs revealed the fact that regarding accuracy, planning in both $+/$-Here-and-Now factors is more enhanced than unplanned here-and-now and there-and-then. Finally, just as fluency, with respect to complexity, the participants' performances are statistically the same in the four different tasks.

Keywords: pre-task planning; Here-and-Now; There-and-Then; second language writing; accuracy; fluency; complexity; Oxford Quick Placement Test 


\section{The effects of simultaneous use of pre-planning along +/-Here-and-Now dimension on fluency, complexity, and accuracy of Iranian EFL learners' written performance}

\section{Introduction}

The past two decades have increasingly eye witnessed great interest in the utilization of tasks in the domain of second language pedagogy as well as Second Language Research (SLR). Based on Tavakoli and Skehan (2005), there are three main causes why task-based research has turned to be the hottest trend in the arena of empirical research for more than 20 years. First of all, research casts light on the statement that task performance in itself instigates inter-language change by making learners to attend to and retain information about the target language as they utilize it. Second, since research distinguishes various features of tasks which affect learner's language processing, it makes empirical principles ready for classroom materials design. Finally, research serves to explore the claim that task design and processing conditions can be selected intentionally by a teacher to guide a learner's focus of attention to particular aspects of the language being learned.

\subsection{Two recent opposing models on Task Complexity}

The study which was conducted here is formed within current SLA theories of task complexity, and it frames one further attempt to investigate the impacts of manipulating several task factors on task performance in a single experimental study. In order to situate the relevant research, an attempt will firstly be made to review the two recent opposing theoretical frameworks on task complexity in task-based SLA research: On the one hand, Skehan and Foster's Limited Capacity Model (The single-resource model) and Robinson's Cognition Hypothesis (Multiple-resource model) on the other hand.

Both Skehan (1998a, 1998b) and Robinson (2001a, 2005, 2007) come to agreement in their predictions of increasing task complexity with respect to the resource-dispersing factors (in Robinson's terminology) in the sense that increasing the cognitive demands of tasks regarding these factors would have a negative effect on the accuracy, fluency, and complexity of learners' oral language production. However, the discrepancy between Skehan (1998) and Robinson (2007) is in their theoretical explanations of the same predictions. Whilst Skehan (1998) and Skehan and Foster (2001) debated the fact that learners have limited attentional resources and, therefore, they have to draw upon a capacity limited pool of resources, Robinson (2001a, 2001b, 2005), however, addresses that learners' attentional resources are not limited, and that multiple and non-competing attentional pools can be accessed.

Skehan (2001) explains that the differential effects of task complexity are due to trade-off effects whereas Robinson (2007) rejects this idea. Furthermore, Skehan (1998) and Robinson (2001a, 2005, 2007) are not in line with each other in their predictions of the effects of increasing cognitive demands of tasks with respect to resource-directing factors on language production. Whereas Skehan (1998) believes that increasing task complexity respecting these factors causes reduced fluency, complexity, and accuracy of oral language production, Robinson (2001a, 2001b, 2003, 2005) argues that increasing task complexity with respect to these factors augments complexity and accuracy but reduces fluency.

\subsection{Pre-task planning (PTP)}

Serving learners with the opportunity to plan a task, therefore, may aid performance. In this study, it is hypothesized that pre-task planning/strategic planning, or lack thereof, might have a significant impact on the enhancement of the learners` complexity, accuracy, and fluency. For one thing, as Skehan and Foster (2001) argue, when language learners are restricted in terms of time, they are quite willing to prioritize meaning over form. On the contrary, when there is no time restriction, learners can take time to formulate more accurate 
structures and correct the inaccurate ones in the 'formulation phase' prior to the 'articulation' (Levelt, 1989). Pre-task planning is a kind of planning which examines how planning prior to performance influences production. As it will be shown elsewhere in this study, this dimension is operationalized through allowing students more time before performance, on the assumption that without time pressure, they will engage in more covert planning activities than students performing under time pressure. Several studies indicate that strategic planning helps to enhance fluency. Studies by Foster and Skehan (1996), Skehan and Foster (1997), Wendel (1997), Mehnert (1998), and Ortega (1999) all report that giving learners the opportunity to plan results in greater fluency (i.e. a faster speaking rate and fewer dysfluencies) (Ellis, 2005). A reasonable assumption is that the length of planning time is positively correlated with the degree of fluency. Mehrnet (1998) set out to investigate this, allocating different groups of learners zero minutes, one minute, five minutes, and ten minutes of planning time. However, the main effect was between the non-planners and the planners.

In contrast to fluency, the effects of strategic planning on accuracy are quite mixed. A number of studies found that strategic planning assisted accuracy only on some structures, some tasks and in some conditions. In terms of the Levelt model, strategic planning can be expected to aid conceptualization but the impact of this may depend on the readiness of learners to shift attention to formulation when performing the task. If they do this, then strategic planning may lead to greater accuracy but if they do not do this, no effect will be evident (Yuan \& Ellis, 2004). The results are clearer for complexity. As for fluency, strategic planning has a definite, positive effect; planners produce more complex language than non-planners (Yuan \& Ellis, 2004).

\section{3 [Here-and-Now] versus [There-and-Then]}

In this study, it is hypothesized that [+/-Here-and-Now] could have an important effect on EFL learners' writing CAF. In retrospect, several studies have examined the effect of manipulating the [+/-Here-and-Now] dimension on L2 spoken narrative discourse. The current study's operationalization of the [+/-Here-and-Now] dimension is similar to the ones in previous studies in (1) the removal/ non-removal of a strip cartoon, and (2) the use of present tense in the [+Here-and-Now] condition and the use of past tense in the [-Here-and- Now] condition, with the exception that the study's focus is on written discourse. According to the Cognition Hypothesis, (1) greater conceptual/communicative demands in the [-Here-and-Now] condition will direct learner's attention to accuracy and complexity (i.e. resource-directing effects) and (2) greater coordination of resources in the [-Here-and-Now] condition will lead to greater fluency and serve to promote the above-mentioned resource-directing effects. Robinson (1995) found positive effects of increasing task complexity from [+Here-and-Now] to [-Here-and-Now] on lexical complexity (i.e. lexical density), and on accuracy as measured in target-like use (TLU) of articles, and a negative effect on fluency as reflected in words per pause (Ishikawa, 2006).

\section{Literature review}

\subsection{Pre-task planning studies}

Kellogg (1988) has considered the fact that the processes learners apply while involved in oral and written performance have a lot of common grounds. In addition, language learners often employ strategies of oral language in writing (Schleppegrell \& Colombi, 1997). Accordingly, so as to gain insights on the impacts of planning in L2 writing, a wide repertoire of literature performed in the areas of both writing and speaking performance must be mentioned and reviewed. Nowadays, L2 researchers have primarily illustrated an interest in whether the manipulation of planned conditions positively affects learners' oral or written performance in terms of accuracy, fluency, and complexity (e.g., Ellis, 1987, 2009; Ellis \& Yuan, 2004; Mehrang \& Rahimpour, 2010; Ortega, 1999; Sangarun, 2005; Skehan \& Foster, 1997, 1999; Tajima, 2003; Tavakoli \& Skehan, 2005; Tuan \& Storch, 2007; Wigglesworth \& Elder, 2010; Wigglesworth \& Storch, 2009).

The first crucial study on planning was performed by Ellis (1987) in which he investigated the impact of 
planning on oral production. Ellis proposed that forms which have not yet been fully automatized by learners are more likely to be accessed and used under the planned condition. He argued that the opportunity for planned output facilitates learners to acquire new, more difficult forms which are eventually internalized in the process of speech output. Ellis's research results showed that the accuracy of performance over the three past tense morphemes was strongly associated with the availability of planning time. The first task demonstrated the highest accuracy of performance and the third task showed the least degree of accuracy. While, Ortega (1999) argued that learners cannot attend to things equally because of attentional limitations while they are involved in a task. Ortega came to the conclusion that planning resulted in greater complexity and fluency in learners' oral performance. However, accuracy produced a mixed conclusion, which indicated improvement only in the use of noun modifiers, but not in the use of articles, in L2 Spanish.

Recently, Ellis (2009) reviewed nineteen studies that investigated the effects of three types of planning (rehearsal, pre-task planning, and within-task planning) on the fluency, complexity, and accuracy of L2 performance. All three types of planning have been shown to have beneficial effects on fluency but the results for complexity and accuracy were more mixed, reflecting both the type of planning and also the mediating role of various factors, including task design and implementation variables and individual difference factors. Overall, these studies demonstrated that pre-task planning aids fluency and complexity but not necessarily accuracy in L2 learners' oral narratives.

A study conducted by Ahmadian and Tavakoli (2011) in an EFL class in Iran, investigated the effects of simultaneous use of careful online planning and task repetition on accuracy, complexity, and fluency in the oral production of EFL learners. The results obtained from one-way ANOVAs revealed that the opportunity to engage simultaneously in careful online planning and task repetition enhances accuracy, complexity, and fluency significantly. In another study in Iranian context by Mehrang and Rahimpour (2010) aimed at investigating the impact of planning conditions on the oral performance of the EFL learners while performing structured vs. unstructured tasks. Results demonstrated that planning time served no impact with regard to the accuracy and fluency of the learners' performances, but resulted in more complex performances when participants conducted the unstructured task. In the meantime, task structure did not effect on the accuracy and complexity whilst promoting the fluency under the planned condition.

Another study done Wigglesworth and Elder (2010) in a testing context, investigated the relationship between three variables in the IELTS oral module (planning, proficiency, and task). Their objective was to determine whether differences in performance emanated from 1 or 2 min of planning time. Also, it aimed to realize the most effective strategies utilized by candidates in their planning. Neither the analysis of the scores nor the discourse analysis illustrated any significant differences in performance according to the amount of planning time learners were equipped with. In the same vein, Mehnert (1998) also discussed the influence of different amounts of planning time on L2 oral performance. This result of Mehnert's seemed to support the concept of trade-off effects between accuracy and complexity offered by Skehan and Foster (1997). When the participants were given 1 minute to plan, accuracy was enhanced. Ten minutes of planning time made it possible for the participants to generate more complex language. Because of their limited capacity for attentional resources, learners have inclination to achieve accuracy or complexity at one time.

Although this suggested that planning time does not positively benefit candidates, Wigglesworth and Elder (2010) have discussed the fact that 1 min of pre-task planning should be considered as an alternative in the test development process in the interests of fairness and to boost the face validity of the test. Unlike most studies on planning, Park (2010) separated pre-task instructions from planning, hence making it evident as to what brought about the improvement in planned performance. Park's (2010) study examined whether pre-task instructions and planning enhance focus on form during task-based interaction. The findings illustrated the fact that irrespective of pre-task instructions and planning opportunity, the learners concentrated on vocabulary. Moreover, whereas pre-task instructions displayed some role for manipulating attention to form, planning did not serve any impact. 
The studies noted above were conducted with regard to the L2 production. As a result, an attempt will be made to mention few studies on the written production of L2 learners. Dellerman et al. (1996) particularly examined the effects of planning in argumentative writing. In spite of the fact that there was no global effect of planning on the quality of written texts, the results displayed that planning focused on logical relationships served a significant impact on the argumentative texts produced. As Dellerman et al. (1996) expected, planning was most influential for non-proficient writers. In another study Ellis and Yuan (2004) examined the effects of different types of planning on L2 narrative writing. Their results can be linked to those obtained in earlier studies (e.g., Mehnert, 1998; Skehan \& Foster, 1997). Attentional resources are limited so that competition takes place in order to achieve goals between accuracy and complexity. The results also seem to support Kellogg's (1988) research results. Kellogg suggested that significant gains in task performance may come only when a strategy allows focus on a single process of writing

\section{$2.2+/$-Here-and-Now studies}

With respect to the Here-and-Now/There-and-Then distinction, this research followed Robinson's (1995) operationalisation. For Here-and-Now, learners were asked to jot down the story in the present while they looked at the strips. For There-and-Then, learners were requested to write the story in the past tense, and they were not allowed to look at the pictures as they performed the task. There were some studies performed as well. Rahimpour (1997) extended Robinson's research by crossing a complexity variable (Here-and-Now) with a condition variable (open vs. closed). Rahimpour hypothesized that the Here-and-Now/There-and-Then narrative would be more complex than the other versions of the task. Rahimpour's results showed that learners who performed the most complex versions of the task were significantly less fluent, with no such large differences regarding either structural or lexical complexity, and with significant improvements with regard to error-free units but not target-like use of articles.

In another study, Iwashita et al. (2001) investigated the effects of manipulating complexity on L2 learners' fluency, complexity, and accuracy. Iwashita et al. found that there were no significant differences between easy and difficult versions of tasks except for accuracy. In the case of immediacy, they found that the more difficult version of tasks, that is, in There-and-Then, triggered higher levels of accuracy, which went against their prediction. Up to the present time, to the researcher`s knowledge, there has been only one study (Gilbert, 2007) the difference of which is, first, on the fact that this research was speech-based and secondly, the instructions were slightly different. A matter of bottom line which is worth mentioning here is the fact that assuming there were some studies on +/-planning as well as +/-Here-and-Now on L2 learners writing, these studies were done separately. What is meant exactly here is the fact that with regard to Writing, there has not been an attempt to merge both a factor of resource-directing(+/-Here-and-Now) and resource-dispersing factor(+/-planning time) simultaneously out of which four conditions grow. Hence, more research needs to be performed in this regard. The present study sets out to investigate how planning time along with +/-Here-and-Now affect EFL Iranians` writing CAF.

Accordingly, in this study, an attempt was made to find the answer to the following three questions:

1. Is writing accuracy affected by $+/-$ planning and increasing task cognitive complexity (that is, +/Here-and-Now)?

2. Is writing fluency affected by $+/$ - planning and increasing task cognitive complexity (that is, +/Here-and-Now)?

3. Is writing complexity affected by $+/$ - planning and increasing task cognitive complexity (that is, $+/$ Here-and-Now)?

For the purpose of answering the above-mentioned questions, the following research null hypotheses were formulated: 
$>$ Ho1: Writing accuracy is not affected by $+/$ - planning and increasing task cognitive complexity (that is, +/- Here-and-Now).

$>$ Ho2: Writing fluency is not affected by $+/$ - planning and increasing task cognitive complexity (that is, + -- Here-and-Now).

$>$ Ho3: Writing complexity is not affected by $+/$ - planning and increasing task cognitive complexity (that is, +/- Here-and-Now).

\subsection{Design}

A quasi experimental design of study will be pursued to answer the research questions. The research will be conducted in an educational context with already formed English language teaching classrooms and addresses the issue of competition for attention i.e. the effect of manipulating task complexity on students' writing CAF.

As far as the independent variable is concerned, four levels of Task Complexity were analyzed:

$>\quad$ Condition 1: Planned Here-and-Now

$>\quad$ Condition 2: Planned There-and-Then

$>$ Condition 3: Unplanned Here-and-Now

$>$ Condition 4: Unplanned There-and-Then

As well as the independent variables mentioned above, there was the set of the three analytic measures of fluency, complexity, and accuracy which will be explained later.

It is worth mentioning the fact that following several studies (Foster \& Skehan, 1996; Mehnert, 1998; Ortega, 1999; Skehan \& Foster, 1997) operationalisation of planning time was 5 minutes for planned narratives and 50 seconds for unplanned ones (enough to understand the story). When planning time was available, subjects were encouraged to take notes on what to write and how to note them down as they planned, but were told they would not be allowed to keep their notes during task performance. With respect to the Here-and-Now/There-and-Then distinction, this research followed Robinson's (1995) operationalisation. For Here-and-Now, learners were asked to jot down the story in the present while they looked at the strips. For There-and-Then, learners were requested to write the story in the past tense, and they were not allowed to look at the pictures as they performed the task.

\section{Method}

\subsection{Participants}

There were 30 Iranian learners of English, both males and females participating in this study. They were learning English as a foreign language at Sadr English Language Institute in Esfahan, Iran. The participants' mother tongue was Farsi, and their age ranged between 18 and 26. They were attending New Interchange $3 \mathrm{~b}$ English course and therefore, their English proficiency level was considered to be lower-intermediate. In order to make sure about the homogeneity of the participants, an Oxford Quick Placement Test (OQPT) version 1 was conducted. According to the level chart of the OQPT, those students whose scores fall between 28 and 36 are considered lower-intermediate. Table 1 shows the descriptive statistics for this test. As it can be seen in the above table, the range of scores obtained by the participants is 29 to 36 which is in congruence with OQPT's level chart. Therefore, it can be claimed that all the participants were the members of the same population. 
Table 1

Descriptive statistics for accuracy

\begin{tabular}{llcccc}
\hline \multicolumn{1}{c}{ Group } & $N$ & Mean & $S D$ & Min & Max \\
\hline P_HN & 30 & .740 & .111 & .47 & .93 \\
P_TT & 30 & .723 & .124 & .46 & .89 \\
UP_HN & 30 & .601 & .097 & .43 & .82 \\
UP_TT & 30 & .593 & .092 & .43 & .73 \\
\hline
\end{tabular}

Note. $\mathrm{P} \_\mathrm{HN}=$ Planned Here-and-Now; P_TT = Planned There-and-Then;

UP_HN = Unplanned Here-and-Now; UP_TT = Unplanned There-and-Then.

\subsection{Materials}

\subsubsection{OQPT}

In order to assess the participants' proficiency level, an OQPT was administered. This test consists of 60 multiple-choice items. The questions measure the test-takers' English language knowledge regarding usage, prepositions, vocabulary in the form of cloze passages and fill-in-the-blank questions (see Appendix A).

\subsubsection{Experimental materials}

For the main experiment of this study, four picture stories were chosen as the materials for data collection. To compensate for the negative effect of participants' knowledge on the selected topics on their writing, it was tried to choose those picture stories with every day subjects. Moreover, four different picture stories were chosen to prevent the practice effect. The picture stories were taken from Teaching the Spoken Language by Brown \& Yule (1983) and Referential Communication Tasks by Yule (1997) (Appendix B). The pictures employed in this research were thought to be especially useful for doing this experiment because they were wordless comic strips, and contained a few characters who were involved in the action, and it had a clear climax and resolution. It was thought to refer to situations all students could be familiar with within their cultural parameters.

\subsection{Procedures}

\section{General procedures}

In the first place 30 EFL students with lower-intermediate English proficiency level were selected. Then, in order to make sure about their homogeneity, an OQPT was administered, and it was found out that they were homogeneous with regard to their English knowledge. The participants were informed that the experiment was not part of their course material, but they would be given extra points for their good writings.

For the next stage, that is, the main experiment, it was decided to give two tasks in a session; in other words, it was decided to do the planned part of the experiment in one session and the unplanned in the second session. Therefore, in the first session, the participants were first given one of the comic strips, and they were asked to look at the pictures for 5 minutes and then with pictures available to them write a here-and-now composition (in present tense). Then, they were given 15 minutes to complete their writings. Having finished the first task, the students were given the second picture. This time, again, they were 5 minutes to study the picture, and then they were asked to write a composition about the story in the picture but use there-and-then style (in past tense) in 15 minutes with the pictures available.

In the second session, that is, the unplanned session, the participants were given the third comic strips and they were given 50 seconds to look at them and understand the story. Then the pictures were collected and they were asked to write the story in the pictures in here-and-now format (in present tense), of course, with the chance of looking at the pictures. After finishing the task which took 15 minutes, the writings were collected and the last set of pictures was distributed among them. In this part, they were given 50 seconds to look at the pictures and 
Mohammadzadeh Mohammadabadi, A., Dabaghi, A., \& Tavakoli, M.

then the pictures were collected. Then, once again, they were asked to write a composition telling the story in the picture in 15 minutes, but this time in there-and-then format (in past tense). It should be reminded that for all the tasks the participants were instructed to write, their compositions is at least 70 words.

\subsection{Scoring}

As Skehan (1996) has pointed out, the general aims for language teaching are to enhance fluency, complexity, and accuracy in learners' production. These three aspects of language performance have also been utilized so as to measure the quality of language production in different studies. In this study, variables pertinent to these three aspects were employed to measure the result of the study.

The participants' writings were considered for the following criteria:

\subsubsection{Complexity}

Complexity refers to how elaborate the language is used in the production. According to Foster and Skehan (1996), complexity reflects how learners can use the forms "closer to the cutting edge of inter-language development" and is more associated with learners' willingness to take risks to use the language with which they are not familiar. For measuring complexity, the criterion of S-nodes per T-units was considered (Gilabert, 2005; Ishikawa, 2006; Rahimpour, 1997; Robinson, 1995). In other words, the number of sentence nodes in writing was divided by the total number of T-units in that writing.

\subsubsection{Fluency}

Fluency refers to the capacity to mobilize the inter-language system to communicate meaning in real time (Skehan, 1996, p. 46).In order to measure the fluency, a measure of words per T-units was adopted (Arent, 2003; Ishikawa, 2006); that is, the total number of words in the writing was divided by the total number of T-units in the narrative.

\subsubsection{Accuracy}

Accuracy is concerned with how well the language is produced in relation to the rule of the target language (Skehan, 1996) and measured in the previous studies by the global indexes such as error-free clauses (e.g., Crookes, 1989) and specific indexes such as correctness of regular simple past tense (as in Ellis, 1987). Here in this study, the accuracy of the writings was measured by calculating the number of error-free T-units divided by the total number of T-units (Arent, 2003; Storch, 2009). Hunt (1966, p. 735), defines T-unit as "one main clause plus whatever subordinate clauses happen to be attached to or embedded within it" (Cited in Rahimpour \& Hosseini, 2010, p. 200). By error-free T-unit, it meant The T-units containing no lexical, grammatical, or spelling errors.

\subsection{Data analysis}

The statistical procedures for this study included both descriptive and inferential statistics. In order to compare and contrast the task regarding the three mentioned criteria, a number of ANOVAs were employed by using the Statistical Procedures for Social Sciences (SPSS) version 16. For each calculation, the related tables and graphs are also presented.

\section{Results}

\subsection{Testing the first null hypothesis}

In order to check the validity of the first null hypothesis, the accuracy of writings of the participants were determined and scored with regard to the error-free $t$-units and the total number of $t$-units. Table 1 shows the 
Effects of simultaneous use of pre-planning along +/- Here-and-Now dimension on written performance descriptive statistics of the scores of accuracy for the four sets of writings and Figure 1 graphically presents the means.

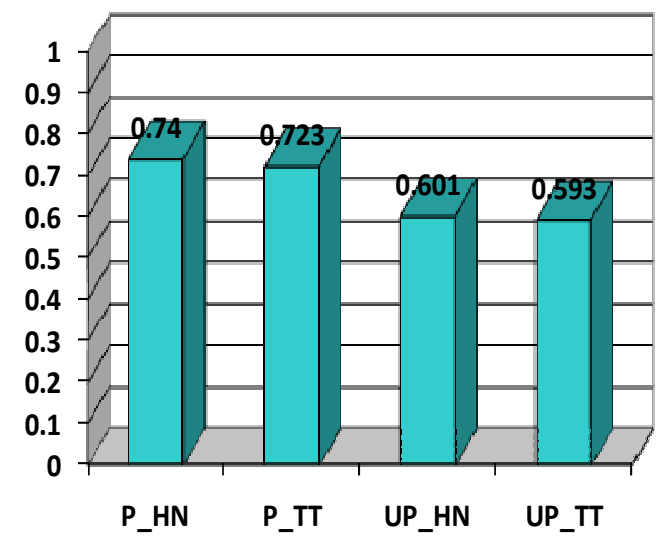

Figure 1. Graphical representation of the means for accuracy

As it can be seen in Table 1 and Figure 1, the means of the four sets of writings are different. In order to find out whether these differences are statistically significant or not, a one-way ANOVA was employed. Table 2 reveals the results of this ANOVA.

Table 2

Results of ANOVA for accuracy

\begin{tabular}{lccccc}
\hline \multicolumn{1}{c}{ Source } & $S S$ & $d f$ & MS & $F$ & Sig. \\
\hline Between Groups & .551 & 3 & .184 & 16.141 & .000 \\
Within Groups & 1.320 & 116 & .011 & & \\
Total & 1.871 & 119 & & & \\
\hline
\end{tabular}

According to Table 2, the amount of F-observed is significant at the probability level of $p=.000$ which means it is statistically significant. To find the exact area(s) of difference(s), a Scheffe post hoc test was run. Table 3 depicts the results of the Scheffe test.

Table 3

Results of the Scheffe post-hoc test for accuracy

\begin{tabular}{lrcc}
\hline Items & Writing & Mean Difference & Sig. \\
\hline P_HN & P_TT & .018 & .938 \\
& UP_HN & $.140^{* *}$ & .000 \\
& UP_TT & $.148^{* *}$ & .000 \\
\hline P_TT & P_HN & -.018 & .938 \\
& UP_HN & $.122^{* *}$ & .000 \\
& UP_TT & $.130^{* *}$ & .000 \\
\hline UP_HN & P_HN & $-.140^{* *}$ & .000 \\
& P_TT & $-.122^{* *}$ & .000 \\
& UP_TT & .008 & .994 \\
\hline UP_TT & P_HN & $-.148^{* *}$ & .000 \\
& P_TT & $-.130^{* *}$ & .000 \\
& UP_HN & -.008 & .994
\end{tabular}

Note. *The mean difference is significant at the 0.05 level **The mean difference is significant at the 0.01 level P_H N = Planned Here-and-Now; P_TT = Planned There-and-Then; UP_HN = Unplanned Here-and-Now; UP_TT $=$ Unplanned There-and-Then. 
Mohammadzadeh Mohammadabadi, A., Dabaghi, A., \& Tavakoli, M.

By referring to Table 3, one can see that the means for planned tasks were greater than those of the unplanned tasks, and that regarding the $+/-$ Here-and-Now tasks, the participants performed better in Here-and-Now task than There-and-Then task in both planned and unplanned conditions, but the differences were not statistically significant. Therefore, the first null hypothesis stating that "writing accuracy is not affected by $+/$ - planning and increasing task cognitive complexity (that is, +/- Here-and-Now)" can safely be rejected, and it can be claimed that +/- planning does affect EFL learners writing performances.

\subsection{Testing the second null hypothesis}

For the second null hypothesis, the fluencies of the four sets of writings were calculated by counting the number of words and dividing it by the total number of t-units. Table 4 shows the descriptive statistics for these scores and Figure 2 demonstrates the means in bar diagram.

\section{Table 4}

Descriptive statistics for fluency

\begin{tabular}{llcccc}
\hline \multicolumn{1}{c}{ Group } & $N$ & Mean & $S D$ & Min & Max \\
\hline P_HN & 30 & 5.62 & .099 & 5.50 & 5.83 \\
P_TT & 30 & 5.63 & .089 & 5.50 & 5.83 \\
UP_HN & 30 & 5.65 & .109 & 5.50 & 5.83 \\
UP_TT & 30 & 5.65 & .101 & 5.50 & 5.83 \\
\hline
\end{tabular}

Note. P_HN = Planned Here-and-Now; P_TT = Planned There-and-Then; UP_HN = Unplanned Here-and-Now; UP_TT $=$ Unplanned There-and-Then .

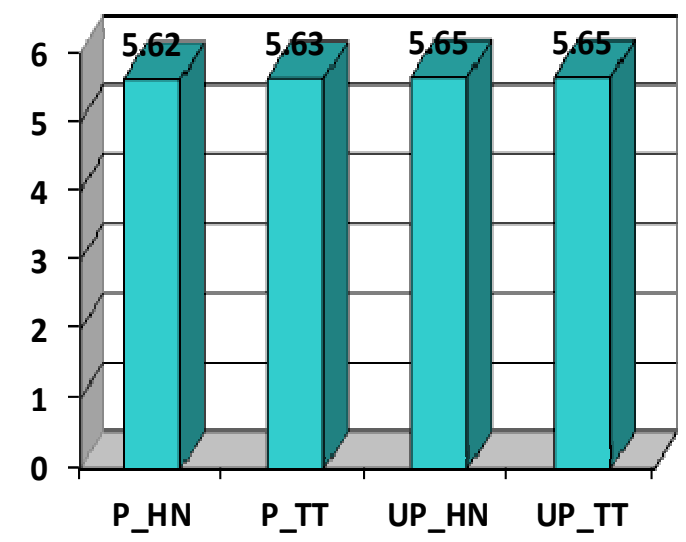

Figure 2. Graphical representation of the means for fluency

According to Table 4 and Figure 2, the means for the four sets of scores are different. To see if these differences are statistically significant, a second one-way ANOVA was applied to the scores. Table 5 indicates the results of this ANOVA.

\section{Table 5}

Results of the ANOVA for fluency

\begin{tabular}{lccccc}
\hline \multicolumn{1}{c}{ Source } & $S S$ & $d f$ & MS & $F$ & Sig. \\
\hline Between Groups & .019 & 3 & .006 & .636 & .594 \\
Within Groups & 1.152 & 116 & .010 & & \\
\hline
\end{tabular}

As it can be seen in Table 5, the amount of F-observed (F-observed $=.636$ ) is significant at the probability level of $p=0.594$ which denotes an insignificant amount of F-observed. Therefore, the second null hypothesis stating that "writing fluency is not affected by +/- planning and increasing task cognitive complexity (that is, +/Here-and-Now)" is retained; in other words, the participants' performances are statistically the same in the four 

different tasks under study (that is, +/- Here-and-Now and +/- planning).

\subsection{Testing the third null hypothesis}

The third null hypothesis considered the complexity of the participants' writings. To measure the complexity of their writings, the number of sentences was divided by the total number of clauses in each of the writings. Table 6 presents the descriptive statistics for this criterion, and Figure 3 gives the graphical representation of the means.

\section{Table 6}

Descriptive statistics for complexity

\begin{tabular}{llllll}
\hline \multicolumn{1}{c}{ Group } & $N$ & Mean & $S D$ & Min & Max \\
\hline P_HN & 30 & .574 & .104 & .40 & .75 \\
P_TT & 30 & .562 & .078 & .42 & .75 \\
UP_HN & 30 & .552 & .088 & .40 & .69 \\
UP_TT & 30 & .550 & .088 & .40 & .69
\end{tabular}

Note. P_HN = Planned Here-and-Now; P_TT = Planned There-and-Then; UP_HN = Unplanned Here-and-Now; UP_TT $=$ Unplanned There-and-Then.

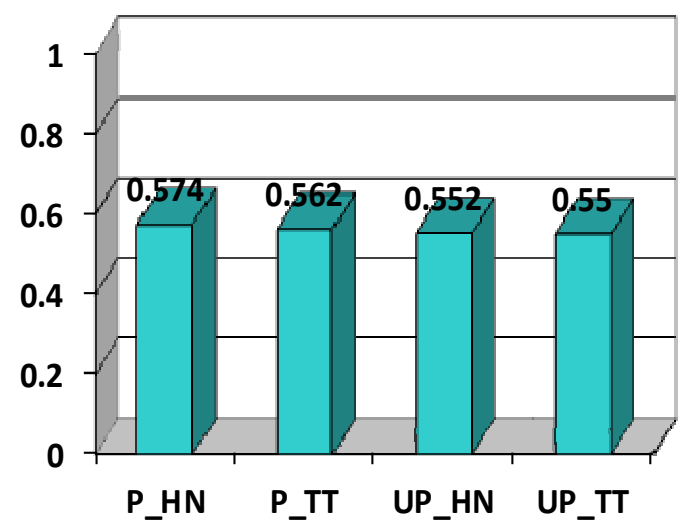

Figure 3. Graphical representation of the means for complexity

Once again, Table 6 and Figure 3 reveal that there are differences between the means of the four sets of scores. To find out whether the differences are statistically significant or not, a third one-way ANOVA was employed. Table 7 gives the results of this last ANOVA.

Table 7

Results of the ANOVA for complexity

\begin{tabular}{lrrrrc}
\hline \multicolumn{1}{c}{ Source } & \multicolumn{1}{c}{$S S$} & $d f$ & MS & $F$ & Sig. \\
\hline Between Groups & .011 & 3 & .004 & .454 & .715 \\
Within Groups & .933 & 116 & .008 & & \\
Total & .944 & 119 & & & \\
\hline
\end{tabular}

By checking the results of the ANOVA in Table 7, one can understand that the amount of F-observed (F-observed $=.454)$ is not statistically significant $(p=.715)$. Therefore, the third null hypothesis which states that "writing complexity is not affected by $+/$ - planning and increasing task cognitive complexity (that is, +/Here-and-Now)" is also retained; in other words, once again, it can be said that the participants' performances are statistically the same in the four different tasks under study (that is, +/- Here-and-Now and +/- planning). 


\section{Discussion of results}

This research has attempted to investigate the impact of Simultaneous Manipulation of Task Complexity along Planning Time and [+/-Here-and-Now] Effects on EFL Learners' Writing CAF. As described and delineated in the result section, the study captured several stimulating findings respecting the influence of simultaneous manipulation of the pre-task planning and [+/-Here-and-Now] on the complexity, accuracy and the fluency of the Iranian EFL learners' writing. The discussion section of this study is presented in two sections. The first section deals with planned/unplanned part of the hypotheses, and the second section discusses the here-and-now vs. there-and-then part.

\subsection{Planned/unplanned results}

Up until now, there has not been plethora of research done regarding this part- that is, +/- planned- in writing. In other words, as it was noted down in the body of literature, some researchers have conducted some studies with the differences that they were primarily speech-based and also secondly, they performed these already-mentioned variables in isolation.

The only research in this regard (to the knowledge of this researcher) is the study done by Gilbert (2007). He found that planning had positive effects on fluency; however, its effect on accuracy and complexity was insignificant. The results of this study do not support Gilbert's findings with regard to fluency and accuracy, because of the fact that the present study found positive effects of planning on accuracy but neither fluency nor complexity. The rest of section, however, compares the results of this study with those accomplished in other language skills, mostly speaking.

The results of this study are in line with the findings of the studies performed by Mehnert (1998), Mochizuki, and Ortega (2008) and Tajima (2003) regarding accuracy and complexity but not fluency. What is common in all these studies is the fact that planning had a significant effect on different measures of fluency (for example, syllables per minute and speech rate) - contrary to the findings of the present study- and on accuracy- similar to the results of this study; however, Mehnert found no effect of planning on complexity which is in line with this study.

Some other studies e.g., Sangarun (2005), Skehan and Foster (1997), Skehan and Foster (2005), Tavokoli and Skehan (2005), and Wigglesworth (1997) stated that planning time affected all three areas, that is, accuracy, fluency, and complexity. All of these studies reported that the planning affected the three measures positively. However, some of these studies, for example, Tavokoli and Skehan (2005) and Wigglesworth (1997), maintained that planning time resulted in greater accuracy, complexity, and fluency in the learners with high proficiency. The results of this study do not concur with the above-mentioned findings.

Another group of studies reported that planning had positive effects on fluency and complexity but not on accuracy (see for example, Wendel, 1997 and Yuan \& Ellis, 2003). Once again, these findings are supported by the findings of this study because, as it was mentioned earlier, the experiment in this study resulted in better accuracy only. Nevertheless, the findings of Rutherford's (2001) experiment showed no significant effect of planning on any of the three measures of accuracy, fluency and complexity. All in all, one main reason for this difference between the results of the present study and the studies mentioned above might be in the language skill under investigation. In other words, all of these studies focused on speaking while this study investigated the effects of planning on writing.

\section{$5.2+/$ - Here-and-Now results}

For this part, only two pieces of research were available to the researcher, one by Gilbert (2007) and the other one by Rahimpour and Hosseini (2010). Gilbert found that There-and-Then conditions resulted in greater accuracy than the Here-and-Now conditions, a result which is in contrast with the results of this study which 
confirm that there is no significant difference between Here-and-Now condition and There-and-Then condition in none of the three areas. The findings of the present study also contradict the results obtained by Rahimpour and Hosseini (2010). They reported that the difference between Here-and-Now condition and There-and-Then condition was significant only in the case of fluency; in other words, the participants' performances in the other two areas, that is, accuracy and complexity, were not statistically different. The findings of this study, again, were not in line with their findings.

\section{Conclusions and recommendations}

In this study, endeavor was made at understanding how different degrees of cognitive complexity affect narrative written production. Specifically, the effects of simultaneous manipulation of $+/$-planning (a resource-dispersing factor) and +/-Here-and-Now (a resource-directing one) impacts were examined. Moreover, this study was rested on the findings of two competing theories the former of which is Skehan and Foster's Limited Attentional Capacity Model and the latter of which is Robinson's Cognition Hypothesis. The first one claimed a better performance on the less complex task, the latter on the complex task.

Based on the results reported and the discussion conducted in the previous sections, several conclusions can be drawn:

$>$ Firstly, With regard to accuracy, when planned here-and now is compared with planned there-and-then, no significant difference can statistically be observed. By the same token, there is no statistically significant difference between unplanned here-and-now and unplanned there-and-then. However, comparing planned conditions- conditions 1 and 2- with unplanned conditions- conditions 3 and 4-, it can be concluded that planning has had a significant impact on the performance of the learners which is in line with the findings of Ellis and Yuan (2004) and +/-Here-and-now does not play a role. Furthermore, when conditions 1 and 4 are compared, it can be concluded that less cognitively demanding tasks are statistically significant than more cognitively demanding tasks which provides support with Skehan's limited capacity hypothesis. Thus the first hypothesis is rejected.

$>$ Secondly, With respect to Fluency, as opposed to Accuracy, the results of this study confirmed the fact that the participants ' performance in all four conditions is statistically the same which led to this fact that the simultaneous manipulation of planning and $+/$-Here-and-Now dimension on fluency does not make a considerable difference. Hence, the second hypothesis is retained.

$>$ Thirdly, regarding complexity, similar to fluency, though there is difference in means of the four conditions of the study, the differences are not considered statistically significant. Consequently, the third hypothesis is retained as well.

$>\quad$ Fourthly, the result of this study corroborated the fact that pre-task planning can successfully confirm the results of many studies which were already performed. Its partially conformity with previous bodies of research can demonstrate a bottom line characteristic of a sound research, that is, the replicability of such a study.

$>\quad$ By and large, it is concluded that Iranian EFL learners' written performance was affected by planning time more than +/-Here-and-Now factor with regard to fluency, complexity, and accuracy measures.

\subsection{Pedagogical implications}

The results obtained out of this study needs to be approached from product-oriented theory in second language writing, particularly, respecting the influence of planning as a main part of writing process. As it was studied and indicated by Dellerman et al. (1996) and Ellis and Yuan (2004), the utilization of planning activity can be considered as an effective pedagogical tool for language learners in order to improve their writing skills. As a consequence, it seems inevitable for language instructors to develop a variety of planning activities in L2 
composition classes. In addition, teachers could help learners to learn how to utilize planning strategies in composition classes by making use of various kinds of pre-planning activities in EFL context, for instance, planned +/- here-and- now versus unplanned +/-here-and-now. Moreover, in EFL context like this one, where the focus is usually on the form of language, teachers can successfully maneuver over students` writing in the classroom by building it into tasks. To put it differently, it is through this way which they are able to easily shift the students' attention from meaning to forms; it can be considered as a fruitful technique.

Finally, the results of this study may provide further evidence in support of the flexibility of task-based language teaching and learning. In the Iranian EFL context, many teachers might avoid using a task-based approach on the account of the fact that it does not provide enough opportunity for language learners to focus on their writing the same as what has been done in this study.

\subsection{Limitations of the study}

As it is crystal clear via any scientific research, nothing can be self-explanatory unless it is proven by observation or experiments. To perform and conduct the observations or experiments is faced with limitations and problems. This study could result in somehow more different results than it did if it was not confronted by the following limitations:

$>\quad$ First and foremost, the sample of the present study was restricted to EFL learners with Farsi as their L1. Hence, this limits the scopes for the generalizability of research findings. Further investigations with samples of more multifarious representation consisting of students from a range of language backgrounds both in EFL and ESL context are highly desirable as long as the current findings are to be applied to any population other than Iranian learners of EFL.

$>\quad$ Secondly, the study investigated only one level of proficiency, i.e. the lower-intermediate level; it does not allow generalizability across a broader range of proficiency. To put it differently, such study needs to be conducted in other levels of proficiency so as to find out the fact if the same results will be accomplished. Learners with weaker or stronger capacities and lower or more language proficiency should be taken into consideration.

$>\quad$ Thirdly, thirty students took part in this study; larger samples, accordingly, more representative of the larger population may yield more conclusive results. Next, this amalgamation of process and activities to be performed in the classroom will definitely require a seasoned teacher not every naïve one could do the job. Then, perhaps the utilization of more valid and reliable techniques and instruments could help researchers accomplish more authentic results than what was obtained now.

$>\quad$ The one to the last limitation is pertinent to the experimental conditions themselves which may naturally exert some restrictions on the generalizability of the results. Because in such a study, the more we try to improve the internal validity, the more we may lose the external validity which is relevant to the generalizability of the findings.

$>\quad$ The last but by no means the least, evaluation along with generalization of findings in human issues is problematic. To put it simply, one can hardly contend that all variables have been controlled throughout the study since some uncontrollable variables may constantly influenced the obtained results. The least of such variables may include the participants' exhaustion, their last night sleeplessness as well as distractions from the environment. All put the researcher into a state of hesitation to contend following a true experimental research design.

\subsection{Suggestions for further research}

Having conducted the study, the following views for further research evolved out: 
$>$ Above all, this study probed the effects of simultaneous manipulation of task complexity along pre-task planning and [+/-Here-and-Now] on EFL learners` writing CAF. Further research could be a need to investigate the effect of simultaneous use of online planning and [+/-Here-and-Now] on complexity, and accuracy as well as fluency.

> Next, this study was essentially a laboratory-based study without considering the qualitative dimensions of task performance. It is a necessity for mixed-method research studies which make it possible for both inter-learners as well as intra-learner variants. Findings obtained from such studies could be more easily brought down to the context of L2 classroom.

Dinally, there is essentiality for longitudinal research. Mostly, task-based research, from whichever paradigm, is cross-sectional and interprets research results for their implications for development. These are obviously interpretations; we desperately need research with a longer timescale that probes directly whether the impacts that can be generated in the short run have implications for language acquisition over time. Inferences in this arena are not enough.

\section{References:}

Ahmadian, M. J., \& Tavakoli, M. (2011). The effects of simultaneous use of careful online planning and task repetition on accuracy, complexity, and fluency in EFL learners' oral production. Language Teaching Research, 15, 35-59. http://dx.doi.org/10.1177/1362168810383329

Arent, R. (2003). Promoting revision and development in L2 writing through a combination-based curriculum. The Korea TESOL Journal, 6(1), 1-26.

Brown, G., \& Yule, G. (1983). Teaching the spoken language: An approach based on the analysis of conversational English. Cambridge: Cambridge University Press.

Crookes, G. (1989). Planning and inter-language variation. Studies in Second Language Acquisition, 11, 367-383. http://dx.doi.org/10.1017/S0272263100008391

Dellerman, P., Coirier, P., \& Marchand, E. (1996). Planning and expertise in argumentative composition. In G. Rijlaarsdam, H. V. d. Bergh, \& M. Couzijn (Eds.), Theories, models and methodology in writing research (pp. 182-195). Amsterdam: Amsterdam University Press.

Ellis, R. (1987). Inter language variability in narrative discourse: Style shifting in the use of the past tense. Studies in Second Language Acquisition, 9, 1-20. http://dx.doi.org/10.1017/S0272263100006483

Ellis, R. (2005). Planning and task-based performance. In R. Ellis (Ed.), Planning and task performance in a second language. Amsterdam, Philadelphia: John Benjamins.

Ellis, R. (2009). The differential effects of three types of task planning on the fluency, complexity, and accuracy in L2 oral production. Applied Linguistics, 30(4), 474-509. http://dx.doi.org/10.1093/applin/amp042

Ellis, R., \& Yuan, F. (2004). The effects of planning on fluency, complexity, and accuracy in second language narrative writing. Studies in Second Language Acquisition, 26(1), 59-84. http://dx.doi.org/10.1017/S0272263104261034

Gilabert, R. (2005) Task complexity and L2 narrative oral production. Unpublished Doctoral dissertation, Universitat de Barcelona.

Gilabert, R. (2007). The simultaneous manipulation of task complexity along planning time and (+/-Here-and-Now): Effects on L2 oral production. International Review of Applied Linguistics in Language Teaching, 45(3), 215-240. http://dx.doi.org/10.1515/iral.2007.010

Hunt, K. (1966). Recent measures in syntactic development. Elementary English, 43, 732-739.

Ishikawa, T. (2006) The Effect of Manipulating Task Complexity Along the [+/-Here-and-Now] Dimension on L2 Written Narrative Discourse.

Iwashita, N., McNamara, T., \& Elder, C. (2001). Can we predict task difficulty in an oral proficiency test? Exploring the potential of an information-processing approach to task design. Language Learning, 51(3), 401-436. http://dx.doi.org/10.1111/0023-8333.00160

Kellogg, R. T. (1988). Attentional overload and writing performance: Effects of rough draft and outline strategies. 
Mohammadzadeh Mohammadabadi, A., Dabaghi, A., \& Tavakoli, M.

Journal of Experimental Psychology: Learning, Memory, and Cognition, 14(2), 355-365.

http://dx.doi.org/10.1037/0278-7393.14.2.355

Levelt, W. (1989). Speaking: From intention to articulation. Cambridge: MA: MIT Press.

Mehnert, U. (1998). The effects of different lengths of time for planning on second language performance.

Studies in Second Language Acquisition, 20, 52-83. http://dx.doi.org/10.1017/S0272263198001041

Mehrang, F., \& Rahimpour, M. (2010). The impact of task structure and planning conditions on oral performance of EFL learners. Proceedia Social and Behavioral Sciences, 2(2), 3678-3686. http://dx.doi.org/10.1016/j.sbspro.2010.03.572

Mochizuki, N., \& Ortega, L. (2008). Balancing communication and grammar in beginning level foreign language classrooms: A study of guided planning and relativization, Language Teaching Research, 12, 11-37. http://dx.doi.org/10.1177/1362168807084492

Ortega, L. (1999). Planning and focus on form in L2 oral performance. Studies in Second Language Acquisition, 21, 108-148. http://dx.doi.org/10.1017/S0272263199001047

Park, S. (2010). The influence of pre-task instructions and pre-task planning on focus on form during Korean EFL task-based interaction. Language Teaching Research, 14(1), 9-26. http://dx.doi.org/10.1177/1362168809346491

Rahimpour, M\& Hosseini, P (2010). The Impact of Task Complexity on L2 Learners `Written Narratives (P., 200).

Rahimpour, M. (1997) Task condition, task complexity and variation in L2 discourse. Unpublished Doctoral dissertation, University of Queensland.

Robinson, P. (1995). Attention, memory, and the "noticing' hypothesis. Language Learning, 45, $283-331$. http://dx.doi.org/10.1111/j.1467-1770.1995.tb00441.x

Robinson, P. (2001a). Cognition and second language instruction. Cambridge: Cambridge University Press. http://dx.doi.org/10.1017/CBO9781139524780

Robinson, P. (2001b). Task complexity, cognitive resources, and syllabus design: A triadic framework for examining task influences on SLA. In P. Robinson (Ed.), Cognition and second language instruction (pp. 287-318). Cambridge: Cambridge University Press. http://dx.doi.org/10.1017/CBO9781139524780.012

Robinson, P. (2005) Cognitive complexity and task sequencing: Studies in a componential framework for second language task design. International Review of Applied Linguistics, 43(1), 1-32. http://dx.doi.org/10.1515/iral.2005.43.1.1

Robinson, P. (2007). Task complexity, theory of mind, and intentional reasoning: Effects on L2 speech production, intention, uptake, and perceptions of task difficulty. International Review of Applied Linguistics in Language Teaching (IRAL), 45(3), 193-213. http://dx.doi.org/10.1515/iral.2007.009

Rutherford, K. (2001). An investigation of the effects of planning on oral production in a second language. Unpublished Masteral thesis, University of Auckland.

Sangarun, J. (2005). The effects of focusing on meaning and form in strategic planning. In R. Ellis (Ed.), Planning and task performance in a second language (pp. 111-142). Amsterdam, Philadelphia: John Benjamins.

Schleppegrell, M., \& Colombi, M. (1997). Text organization by bilingual writers: Clause structure as a reflection of discourse structure. Written Communication, 14(4), 481-503. http://dx.doi.org/10.1177/0741088397014004003

Skehan P., \& Foster, P. (1999). The influence of task structure and processing conditions on narrative retellings. Language Learning, 49(1), 93-120. http://dx.doi.org/10.1111/1467-9922.00071

Skehan, P. (1996). A framework for the implementation of task-based instruction. Applied Linguistics, 17(1), 38-62. http://dx.doi.org/10.1093/applin/17.1.38

Skehan, P. (1998a). Task-based instruction. Annual Review of Applied Linguistics, 18, 268-286. http://dx.doi.org/10.1017/S0267190500003585

Skehan, P. (1998b). A cognitive approach to language learning. Oxford: Oxford University Press. Skehan, P. (2003). Task-based instruction. Language Teaching, 36, 1-14. 
Effects of simultaneous use of pre-planning along +/- Here-and-Now dimension on written performance http://dx.doi.org/10.1017/S026144480200188X

Skehan, P., \& Foster, P. (1997). Task type and task processing conditions as influences on foreign language performance. Language Teaching Research, 1, 185-211. http://dx.doi.org/10.1177/136216889700100302

Skehan, P., \& Foster, P. (2001). Cognition and tasks. In Robinson, R., (Ed.), Cognition and second language instruction. New York Cambridge University Press. http://dx.doi.org/10.1017/CBO9781139524780.009

Storch, N. (2009). The impact of studying in a second language (L2) medium university on the development of L2 writing. Journal of Second Language Writing, 18, 103-118. http://dx.doi.org/10.1016/j.jslw.2009.02.003

Tajima, M. (2003). The effects of planning on oral performance of Japanese as a foreign language. Unpublished Doctoral dissertation, Purdue University.

Tavakoli, P., \& Skehan, P. (2005). Strategic planning, task structure and performance testing. In R. Ellis (Ed.), Planning and task performance in a second language (pp. 239-273). Amsterdam, Philadelphia: John Benjamins.

Tuan, T. A., \& Storch, N. (2007). Investigating group planning in preparation for oral presentations in an EFL class in Vietnam. RELC Journal, 38(1), 104-124. http://dx.doi.org/10.1177/0033688206076162

Wendel, J. N. (1997). Planning and second-language narrative production. Unpublished Doctoral dissertation, Temple University, Philadelphia, PA.

Wigglesworth, G. (1997). An investigation of planning time and proficiency level on oral test discourse. Language Testing, 14, 85-106. http://dx.doi.org/10.1177/026553229701400105

Wigglesworth, G., \& Elder, C. (2010). An investigation of the effectiveness and validity of planning time in speaking test tasks. Language Assessment Quarterly, 7(1), 1-24.

Wigglesworth, G., \& Storch, N. (2009). Pair versus individual writing: Effects on fluency, complexity and accuracy. Language Testing, 26(3), 445-466. http://dx.doi.org/10.1177/0265532209104670

Yule, G. (1997). Referential communication tasks. Hillsdale, NJ: Erlbaum. 
Mohammadzadeh Mohammadabadi, A., Dabaghi, A., \& Tavakoli, M. 